\title{
Modelo Geral da Criatividade
}

\author{
Igor Reszka Pinheiro ${ }^{1}$ \\ Universidade Federal de Santa Catarina
}

\begin{abstract}
RESUMO - Através de um ensaio crítico-analítico, este artigo revisa o entendimento da criatividade, propondo um modelo que se sustenta nas mais recentes contribuições das ciências cognitivas. Partindo da lógica do processamento de distribuição paralela, o Modelo Geral da Criatividade organiza os vetores da fluência e do grau de divergência, oferecendo uma base conceitual comum para os diversos estudos da criatividade, assim como, indicações mais precisas para a definição de métricas e métodos na pesquisa neurológica. A análise dos vetores da criatividade, seus limites e sua dilatação temporal, se apropria de diversos termos para culminar na assertiva de que o estado de criação consiste de um determinado equilíbrio e não da mera dispersão.
\end{abstract}

Palavras-chave: criatividade; fluência; grau de divergência; equilíbrio.

\section{General Model of Creativity}

\begin{abstract}
By means of a critical-analytical essay, this paper reviews the understanding of creativity, and proposes a model supported by cognitive sciences latest contributions. Starting from the parallel distribution processing logic, the General Model of Creativity organizes both vectors of fluency and divergence degree, offering an unified conceptual basis for creativity's studies, as well as some precise directions for methodological definitions in neurological research. The analysis of creativity's vectors, their limitations, and temporal repercussions, appropriates itself of many terms in order to underline that the state of creation consists on a specific equilibrium instead of divergent thinking.
\end{abstract}

Keywords: creativity; fluency; divergence degree; equilibrium.

O fenômeno da criatividade por muitos anos foi tido como um ato místico, incompreensível e inexplicável, capaz de igualar o homem ao divino por meio da criação (Dollinger, 2007). Neurologistas, psicólogos, cientistas sociais, publicitários e pesquisadores das áreas mais diversas, da inteligência artificial à poesia, buscaram respostas para a pergunta: é possível explicar a criatividade? Apesar dessas áreas convergiram para a resposta 'sim', as tentativas de expressar de maneira absoluta os seus pontos de vista fazem com que as divergências sejam a regra e a unanimidade, a exceção (Pinheiro \& Pinheiro, 2005).

Para pesquisadores que trabalham com a abordagem da inteligência artificial, por exemplo, a criatividade é compreendida como uma resposta impossível em uma busca heurística (Boden, 1996/1999). Já a área da metodologia de projetos afirma que soluções criativas são encontradas por meio da reorganização de informações (Baxter, 1995/2000; Munari, 1981/1998), ou seja, da mudança de uma gestalt - qualidade de um conjunto na qual o todo possui um significado diferente da soma das partes - para outra. Uma terceira opinião, aquela que está voltada para a inventividade, tem para si que criatividade é a remoção de contradições (Manzini, 1993; Schwartz, 1992/1992). A Psicologia, por fim, confere a esse termo uma definição mais restritiva, a qual, além de exigir a sempre referida originalidade, também requer utilidade, abrangendo a discussão sobre juízo de valor (Sternberg, 1999/2000; Ward, 2007).

1 Endereço para correspondência: Rua Heitor Luz, 225, Apto. 205, Centro. Florianópolis, SC. CEP 88015-500. E-mail: pinheiro_ir@yahoo.com.br.
Independentemente da conceituação atribuída, o fato é que a criatividade é descrita, ao mesmo tempo, como um atributo e como um processo que se verifica e se desenvolve no nível do indivíduo e da sociedade (De Masi, 2002/2003; Galvão, 1999; Predebon, 1997). Apesar de inata (De Bonno, 1967/2002; Ostrower, 2002; Wechsler, 2002), portanto, a criatividade está intimamente relacionada a fatores culturais, sócio-econômicos, educacionais e pessoais (Eysenck, 1996/1999). Se, por um lado, Gardner (1996/1999) considera que a criatividade somente se manifesta quando o indivíduo for dotado de especialização em um determinado campo, o que é confirmado por Amabile e Gryskiewicz (1989) ao ressaltarem a importância, beirando à dependência, do aprendizado e da experiência para a realização criativa, por outro lado, Kuhn (1962/1992) se opõe a essa sugestão ao estabelecer que as inovações frente à ciência normal tendem a surgir entre os pesquisadores mais novos, e não entre os mais experientes.

Tal conflito de posicionamentos não é raro, especialmente ao se parear os casos de criatividade artística com os de criatividade científica. "Como podemos definir criatividade como um único constructo que unifica o trabalho de Leonardo da Vinci e Marie Curie, de Vincent Van Gogh e Isaac Newton, de Toni Morrison e Albert Einstein e de Wolfgang Mozart e Nicolaus Copernicus?” (Sternberg, 1999/2000, p. 332). As respostas variam, basicamente, entre a abordagem da produção divergente (Wechsler, 2002) e a teoria de investimento da criatividade (Sternberg, 1999/2000). Enquanto a abordagem clássica de Guilford tem como foco o objeto da criatividade - as ideias em si - concebendo-a como um 
padrão de respostas diversas a uma mesma questão, a teoria contemporânea de Sternberg enfoca a pessoa criativa, a qual é capaz de investir em boas ideias quando elas ainda possuem pouca aceitação, buscando lucro - utilidade - pela obtenção de reconhecimento ou retorno através do tempo (Matlin, 2003/2004).

As características dos indivíduos criativos não são menos controversas, pois, se comparados os atributos listados por diferentes autores, os traços distintos, até divergentes, superam as coincidências (Pinheiro \& Hartamann, 2005). Apresenta-se, na Tabela 1, para ilustrar o referido, os conjuntos de traços de personalidade conferidos às pessoas criativas segundo Eysenck (1996/1999) - 13 itens - e Wechsler (2002) - 15 itens -, dentre os quais somente cinco são comuns (independência, abertura, interesse, auto-aceitação e flexibilidade). Por sua vez, impulsividade e introversão, atitudes sociais e anti-sociais, dentre outros, aparentam tratar de diferentes grupos ou, mesmo, anular-se. Pondera-se, inclusive, que a razão para o sucesso criativo dos indivíduos estudados por Mackinnon e citados por Eysenck (1996/1999) seja, exatamente, a tensão gerada por esses traços contraditórios da personalidade.

Mais do que contrariedade, porém, esses traços apresentam uma nítida complementaridade, caso se supere o paradigma do estímulo e inibição, tão corrente na psicologia e neurociências (Bogacz, 2007; Sakagami, Pan \& Uttl, 2006). Em qualquer atividade mental de alto nível como a tomada de decisão, o controle das emoções e, é claro, a criatividade, acredita-se (e.g., Kolb \& Whishaw, 2001/2002; Munro \& cols., 2007; O'Reilly, Dunbar \& Bentall, 2001) que um estímulo A qualquer pode ser afetado por um contra-estímulo B, sendo inibido, o que resulta em um padrão nulo $(\mathrm{A}+\mathrm{B}=0)$. Essa massificação da lógica booleana, contudo, ignora que a homeostasia tanto da estrutura cerebral quanto do comportamento humano é um construto dinâmico, no qual qualquer estímulo A que enfrente um contra-estímulo $\mathrm{B}$, assume um estado $\mathrm{C}$, diferente de $\mathrm{A}$, de B e de zero ( $A+B=C$ ) (Apolloni \& Bassis, 2007). Seguindo esse raciocínio, características aparentemente antagônicas, apresentadas na Tabela 1, como "presença e atitudes sociais" e "uma atitude anti-social" - respectivamente os números 9 e 10 de Eysenck - são, em verdade, somadas para se atingir um estado ainda mais complexo.

Em ordem de desmistificar esse e outros mitos, este artigo examina e organiza os eixos e vetores que se adicionam para compor o fenômeno da criatividade, propondo um modelo geral, que se justifica, tanto na falta de uma base comum para os diversos estudos interdisciplinares desse crescente campo (Dietrich, 2007), quanto na necessidade de indicações mais precisas para a definição de métricas e métodos na pesquisa neurológica (Fink, Benedek, Grabner, Staudt \& Neubauer, 2007). Circunscrever precisamente esse termo simultaneamente tão difundido e tão pouco delimitado, portanto, consiste de um esforço em atualizar as referências datadas da década de 60, por muito tempo utilizadas mais para guiar os experimentos realizados nos últimos anos do que apenas para ilustrar o cenário histórico dessa área.

\section{Os Eixos da Criatividade}

Não raro, apesar de ainda emergente, é divulgada a ideia de que a atuação dos processos mentais de alto nível caracteriza-se pela formatação em rede do neocórtex, o qual integra e coordena as funções mais básicas do cérebro (Goldberg, 2001/2002). Nisso, as funções executivas passam a ser tratadas como um continuum que se inicia no alto rendimento, passa pela zona normal e finda em uma determinada patologia (e.g., Baylor, 1997; Julien, O’Connor \& Aardema, 2007; O’Reilly \& cols., 2001; Seldon, 2007). Ao tentar seguir essa mesma corrente e construir uma linha da criatividade, percebe-se, contudo, que as suas características são demasiadamente amplas para se relacionarem de maneira retilínea (ver Tabela 1). A proposta do modelo que será aqui exposto, por conseguinte, baseia-se na complementaridade das principais funções de alto nível, às quais, quando soma-

Tabela 1. Traços de personalidade das pessoas criativas.

\begin{tabular}{ll}
\hline Conforme Eysenck (1999, p. 216) & Conforme Wechsler (2002, pp. 72-73) \\
\hline 1. Independência de atitude e comportamento social & 1. Confiança em si mesmo ou autoconceito positivo \\
2. Dominação & 2. Pensamento original e inovador \\
3. Introversão & 3. Alta sensibilidade externa e interna \\
4. Abertura a estímulos & 4. Fantasia e imaginação \\
5. Interesses amplos & 5. Inconformismo \\
6. Auto-aceitação & 6. Independência de julgamentos \\
7. Intuição & 7. Abertura a novas experiências \\
8. Flexibilidade & 8. Sentido de destino criativo \\
9. Presença e atitudes sociais & 9. Idéias elaboradas e enriquecidas \\
10. Uma atitude anti-social & 10. Preferência por situações de risco \\
11. Preocupação com normas sociais & 11. Alta motivação e curiosidade \\
12. Radicalismo & 12. Elevado senso de humor \\
13. Rejeição a restrições externas & 13. Impulsividade e espontaneidade \\
& 14. Fluência e flexibilidade de idéias \\
\hline
\end{tabular}


das, são suficientes e necessárias para contemplar todas as facetas da criação.

Partindo desse ponto, inicia-se a seleção das funções que compõem os eixos da criatividade na unidade fundamental de qualquer atividade mental, assim como de todo sistema nervoso, o neurônio (Kolb \& Whishaw, 2001/2002). Compreendendo que a sua atuação em conjunto opera na forma de rede - processamento de distribuição paralela - (Matlin, 2003/2004), é possível analisar o conexionismo segundo a configuração e o tipo de ligação (Apolloni \& Bassis, 2007). Como ambas as informações possuem valores absolutos e relativos, organiza-se a atividade do todo em duas dimensões não concorrentes, logo, perpendiculares entre si, cada qual com uma medida referente à configuração e ao tipo de ligação da rede. Eysenck (1996/1999), Ward (2007), Fink e cols. (2007), dentre outros, parecem concordar que esses mesmos eixos consistem do grau de divergência e da fluência (Figura 1).

O grau de divergência - eixo absoluto - representa a distância entre dois dados, os quais podem estar concatenados (configuração) e aglomerados (tipo de ligação), simultaneamente. Enquanto o primeiro vetor desse mesmo eixo refere-se à capacidade de organizar, ao sequenciar, as informações, caracterizando o pensamento lógico (McInerny, 2004/2006), o segundo, e oposto, designa o pensamento intuitivo, o qual processa a quantidade total dos estímulos aferentes em um núcleo, sentenciando uma tendência (Baylor, 1997). Apesar da natureza oposta, o que torna tentadora a crença de que lógica e intuição se inibem, reforça-se a ideia de que a somatória desses vetores, sim, geram um terceiro valor - desvio padrão - que figura somente em um eixo $Z$.

Seja pelo excesso de lógica, seja devido à falta de intuição, quando o vetor resultante desse eixo pende para o valor positivo, por convenção, o modus operandi do sujeito apresenta um nítido cartesianismo, caracterizando pensamentos claros, objetivos, elaborados, enriquecidos e, principalmente, imparciais. Típico instrumento da ciência, o pensar lógico baseia-se no argumento, o qual organiza os dados segundo as similaridades e diferenças, gerando cadeias lineares de informações, o que promove grande precisão ao custo de muito tempo de processamento (McInerny, 2004/2006). No extremo positivo desse eixo, consequentemente, encontra-se a psicopatia, enfermidade cujos sintomas são, exatamente, o

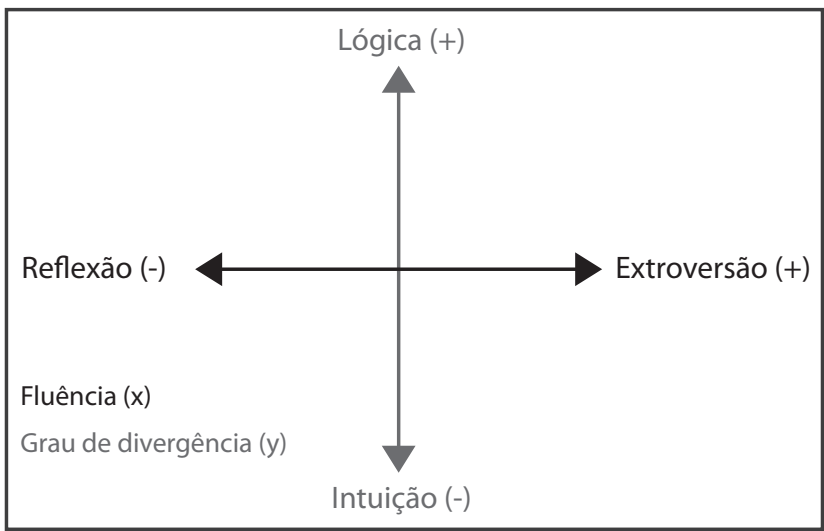

Figura 1. Fluência [vetores pretos] x Grau de divergência [vetores cinzas]. excesso de pragmatismo e a ausência de empatia (Munro \& cols., 2007), principal característica da intuição.

Colocar-se no lugar de outra pessoa consiste em nada mais que atribuir a si, mentalmente, a mesma categoria de outrem, ou seja, permitir que todos os mecanismos fisiológicos de seu corpo reajam em conformidade com os sinais físicoquímicos percebidos desse alguém, mesmo sem a clareza desses indícios (Brendtro \& Longhurst, 2005). A empatia, nesse sentido, juntamente com a flexibilidade, a imaginação, o senso de humor e o uso constante de analogias e metáforas, é o predicado mais comum daqueles cujo valor negativo do grau de divergência supera o positivo (O'Reilly \& cols., 2001). Todos esses traços de personalidade baseiam-se na capacidade rápida - talvez instantânea - de distinção entre categorias absolutas, mesmo que em detrimento da exatidão das informações. É possível saber quando alguém tenta ludibriar, mas não o grau da verdade; é possível prever uma futura tempestade tropical, mas nunca a velocidade máxima dos ventos; é possível equacionar rapidamente qualquer problema complexo e vislumbrar a sua tendência de progressão, mas jamais analisar cada variável individualmente. No limite inferior (negativo) desse continuum, portanto, encontra-se a esquizofrenia, patologia associada ao déficit ou desordem do córtex pré-frontal - tradicionalmente visto como o centro lógico do cérebro - e à manifestação de sintomas positivos como a alucinação e o delírio, fruto de uma generalização categórica desmedida (Seldon, 2007).

Já a fluência - eixo relativo - refere-se à frequência do fluxo de informações processadas, tanto no que diz respeito à direção (configuração) quanto à dispersão (tipo de ligação). Se, por um lado, uma mesma linha de pensamento pode ser trilhada indefinidamente, entrando em looping com uma determinada frequência, caracterizando o estado reflexivo (Julien \& cols., 2007), por outro, diversas cadeias de ideias são capazes de coexistir concomitantemente, espalhando a atenção, típico do padrão extrovertido (Rietzschel, Nijstad, \& Stroebe, 2007). É importante ressaltar que, neste artigo, não se faz referência à extroversão freudiana (atitude do indivíduo que dirige sua energia psíquica para o exterior), mas ao proporcionalmente elevado potencial de troca entre categorias de pensamento.

Reflexão, nesse caso, deixa de ser sinônimo de introversão, estado em que se encontra aquele cujo vetor positivo da fluência está próximo do zero. Refletir consiste, por conseguinte, do ato de repassar ideias, aprofundando, a cada ciclo, o domínio de um mesmo tópico (Rietzschel \& cols., 2007). As características mais comuns das pessoas predominantemente reflexivas são: a timidez, a alta sensibilidade, a irritabilidade, o estabelecimento claro de rotinas e as atitudes anti-sociais em geral. Na falta do seu vetor complementar e em seu auge, esse modo de pensar culmina nos transtornos obsessivos compulsivos (TOC), notoriamente diagnosticados pela persistência de pensamentos ou impulsos de maneira repetitiva e alienatória (Julien \& cols., 2007).

Em contraste, a extroversão é o padrão de pensamento em que a quantidade é mais valorizada que a qualidade e a horizontalidade mais que a profundidade (Rietzschel \& cols., 2007). Pensamentos pouco densos, porém, muito amplos e divergentes são, portanto, a base de traços como a curiosidade, a independência, a sociabilidade, a impulsividade, a 
abertura a novas experiências e a preferência pelo arriscado. Uma última patologia se encontra no extremo desse vetor, não surpreendendo aqueles muitos educadores que constantemente associam liberdade e criatividade: o transtorno de déficit de atenção e hiperatividade (TDAH) (Cramond, 1994).

A corriqueira associação entre loucura e genialidade surge, destarte, da popularização apenas dos casos mais notórios, e extremos, de criatividade, nos quais seu protagonista beira, ao menos, um dos pólos do modelo (Santosa \& cols., 2007). Muito mais comum, todavia, é a criatividade modesta, assim como a presença de características mistas, tais como a contemplação, a admiração, o receio e a autoconfiança. Nisso, segue-se para um segundo nível de análise, abandonando os eixos que compões a criatividade para focalizar os quadrantes resultantes da interação desses primeiros.

\section{Limites e Quadrantes}

Considerando que cada vetor dos eixos $\mathrm{X}$ e $\mathrm{Y}$ varia de $0 \%$ a $100 \%$, matematicamente percebe-se que o universo no qual estão inseridos os continua possui os seus limites definidos entre $\mathrm{X}$ igual a -1 e $\mathrm{Y}$ igual a -1 , e $\mathrm{X}$ igual a 1 e $\mathrm{Y}$ igual a 1. No interior desse espectro, logo, encontram-se quatro quadrantes, cada qual relacionando dois dos vetores do modelo. Segundo Bogacz (2007), o comportamento baseado em estruturas conflitantes de estímulo difuso - rede neural - obedece a uma relação exponencial, na qual a taxa de ativação de cada unidade se torna cada vez mais sensível à excitação. Isso significa que a dependência de $\mathrm{X}$ e Y é tal que à medida que um dos vetores cresce os seus correspondentes perpendiculares necessitam de cada vez menos estimulo para gerar um mesmo estado mental limítrofe (Figura 2).

A configuração resultante faz referência a Perkins (1996/1999) que, utilizando a sua analogia de Klondike, discrimina quatro situações que limitam a criatividade: o problema da raridade, o do isolamento, o do oásis e o do

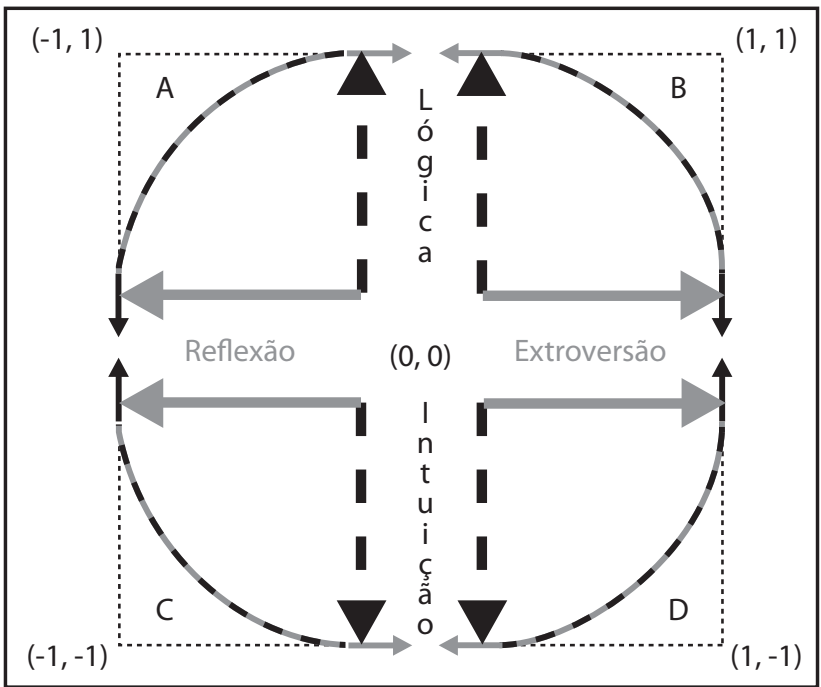

Figura 2. Relação inversamente exponencial dos vetores. Fluência e sua excitação limítrofe [vetores cinzas e contínuos] x Grau de divergência e sua excitação limítrofe [vetores pretos tracejados]. Conjunto universo [área pontilhada]. A - medo; $\mathrm{B}$ - orgulho; $\mathrm{C}$ - raiva e; $\mathrm{D}$ - fanatismo. platô, ou, conforme interpretação psicológica, o medo, a raiva, o orgulho e o fanatismo, respectivamente. Mesmo que de maneiras diferentes, os quatro problemas inibidores da criatividade são basicamente motivos para a rigidez mental, de um corpo individual ou coletivo, acarretando a chamada "resistência a mudanças" (De Masi, 2002/2003).

Optar pelo convencional ou pelo novo é uma questão de tomada de decisão e, portanto, o resultado da equação entre a quantidade de recompensa e o tempo necessário para usufruir desse mesmo ganho (Kalenscher, Ohmann \& Güntürkün, 2006). O estado de medo (Área A na Figura 2) consiste da consciência de que a recompensa oferecida pela sociedade e pela natureza está distribuída de forma esparsa em um vasto espaço de possibilidades, sendo estatisticamente mais provável que uma mudança acarrete em perda do que em ganho (Coricelli, Dolan \& Sirigu, 2007). Na vida prática, com o passar do tempo, as frustrações e o desconforto físico tendem classificar a instabilidade como algo a ser evitado, acarretando simultaneamente nos comportamentos estereotipados e na falta de criatividade (Mason, Clubb, Latham \& Vickery, 2007).

Ainda no vetor lógico encontra-se o orgulho (Área B na Figura 2), traço raramente citado nos anais da criatividade e socialmente celebrado. À semelhança de um oásis, contudo, boas ideias habitualmente fascinam os seus descobridores e adeptos ao suprir as suas necessidades por um período finito de tempo, após o qual suas qualidades impreterivelmente decaem, mantendo presas a si qualquer um que não encontre outro caminho óbvio (Pinheiro, 2004). Rietzschel e cols. (2007) demonstram, em um estudo controlado, que a performance criativa de especialistas diversos é superior à daqueles especialistas de uma única área, pois esses últimos costumam se manter fixos em um número menor de categorias de respostas.

O estresse, ou sua expressão mais comum, a raiva (Área C na Figura 2), por sua vez, deriva do fato de que as áreas de recompensa se encontram isoladas ou semi-isoladas, tornando penoso o esforço de vincular conceitos aparentemente distantes e se fazer entender (Perkins, 1996/1999). Em se tratando de pessoas prioritariamente reflexivas e intuitivas, esse estado se manifesta sempre que há excesso de ruído no ambiente (Belojevic, Splepcevic \& Jakovljevic, 2001), falta de reconhecimento junto aos pares ou, genericamente, através da sensação de incompreensão (Brendtro \& Longhurst, 2005). Enquanto os indivíduos com medo ou orgulho limitam a sua criatividade pela falta de opções, aqueles com raiva, por conseguinte, deixam o seu potencial inerte devido à incapacidade de concentração e seleção de uma alternativa dentre as várias que ele vislumbra, persistindo na alienação.

Por fim, quando o conservadorismo supera qualquer possibilidade de inovação, chega-se ao dogmatismo ou, ainda, ao fanatismo (Área D na Figura 2), conceito definido como atitude ou pensamento que se norteia por uma adesão irrestrita a princípios tidos como incontestáveis. Nesse caso, ao se deparar com uma ampla gama de possibilidades, a decisão de permanecer inflexível resulta da convicção de que todos os caminhos levam ao mesmo destino (Dollinger, 2007). Apesar de estar constantemente relacionado à religião, o fanatismo se declara nas escolhas de base ideológica em geral, as quais 
ignoram a máxima taxa de retorno, pois sempre empregam o mesmo critério de avaliação (Bogacz, 2007).

Seria ingênuo não considerar a plasticidade cerebral do ser humano e deduzir que cada pessoa ocupa um lugar definido e estático nesse gráfico, restringindo o seu comportamento às atitudes típicas de um único quadrante (Duffau, 2006). E comum a constante oscilação entre os diversos pontos do modelo, especialmente após eventos traumáticos em ambos, corpo e mente, caso a distinção se aplique. Boa parte dos relatos históricos da criatividade, inclusive, se sustentam em uma narrativa cujo ponto de inflexão corresponde ao ápice das criações (Schaffer, 1996/1999). Todas essas referências culminam na assertiva que baliza esta proposta: a criatividade se encontra no ponto central dos eixos.

\section{O Ponto da Criatividade}

Em resposta à tão rotineira falácia do pensamento divergente, criticada por Dietrich (2007), o modelo proposto encontra, exatamente no ponto de equilíbrio entre os quatro vetores que compõem os seus eixos, o estado de inspiração, a chamada criatividade (Figura 3). Eis o principal elo que vincula os exemplos de criatividade artística, científica e demais: a capacidade de adquirir o estado mental complementar sem abdicar da sua já preponderante área de domínio. $\mathrm{O}$ que Einstein fez, por exemplo, foi adicionar intuição à tão lógica física, ao olhar para todas as informações da estrutura newtoniana e reorganizá-las, concebendo um novo arranjo para as partes já existentes (De Bono, 2002/1967). As melhores obras do esquizofrênico Van Gogh foram, igualmente, pintadas após a sua internação e tratamento em um sanatório, provendo-o com lucidez (Gombrich, 1950/1999). Atribui-se aos últimos quartetos de Beethoven a sua genialidade, os quais foram compostos somente após o comprometimento da sua audição, sem a qual foi possível ignorar as críticas externas, dando consistência aos seus próprios diálogos interiores (De Masi, 2002/2003). Na reflexiva esfera empresarial, uma das técnicas mais utilizadas, de estímulo à solução criativa de problemas, é o brainstorming, cujo princípio é a

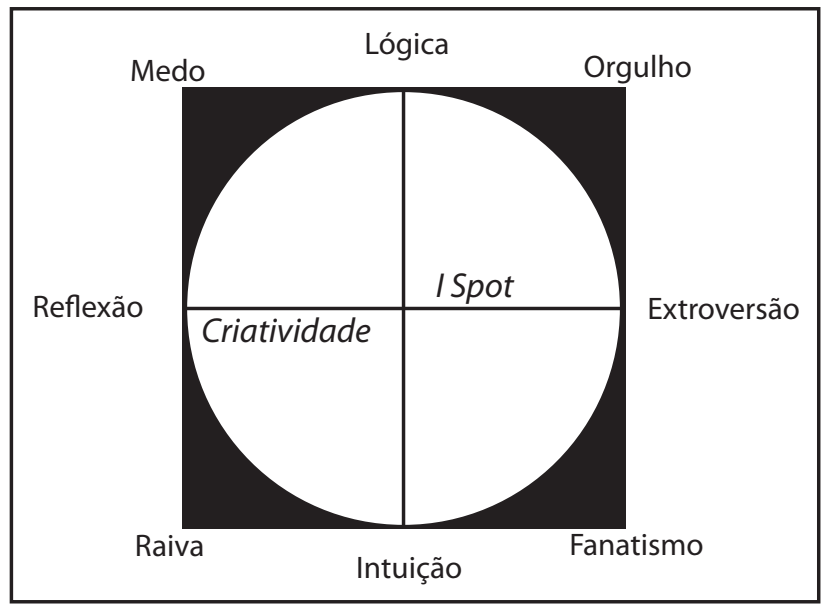

Figura 3. Modelo Geral da Criatividade. Espaço conceitual [área branca]. Resistência a mudanças [área preta]. I Spot - criatividade [interseção dos eixos]. expressão contínua de ideias sem o juízo crítico (Claxton \& Lucas, 2004/2005).

Percebe-se, inclusive, que a metodologia empregada em serviço da criatividade é, em geral, subdividida em etapas que varrem o espectro do modelo, se fazendo útil ao proporcionar a complementaridade de cada situação (Pinheiro \& Pinheiro, 2006). A busca por referências só é benéfica, e somente só, por conseguinte, aos casos que pecam pela falta de lógica, assim como o cruzamento de informações o é aos que necessitam de mais extroversão, a geração de analogias o é aos que demandam intuição e a incubação o é aos que requerem reflexão (Claxton \& Lucas, 2004/2005). Isso corresponde a um giro completo no sentido horário do modelo.

Vários ciclos, porém, são sugeridos nesses métodos de estímulo à solução criativa, uma vez que o desvio padrão da soma dos vetores é diretamente proporcional à amplitude do ineditismo e à funcionalidade da ideia, produto ou processo do projeto (Baxter, 1995/2000), até o limite de 1. Enquanto o quesito novidade aparenta estar relacionado ao eixo do grau de divergência, a utilidade concorre com a fluência, acentuando qualquer assimetria, o que leva aos quatro problemas da criatividade.

Uma grande área, cerca de 3/4 do todo, contudo, permanece livre de qualquer entrave e ainda fora do eixo central. A essa região (área branca na Figura 3) se credita a muito referida exploração do espaço conceitual ou, segundo outra legenda, ao período que precede uma mudança estilística radical (Boden, 1996/1999). Esse é o tempo necessário para a assimilação das novas variáveis - tecnologia, cultura, meio ambiente, know how etc. - propostas pelo emergente paradigma, o qual, antes de ser novamente falseado, tende ao esgotamento através da plena compreensão e superação (Martindale, 1996/1999).

O insight, por sua vez, ocorre apenas no auge da criatividade, momento em que os vetores se equilibram, resultando no ponto $\mathrm{X}$ igual a 0 e Y igual a 0 , nominado aqui de I Spot. Não bastasse o meio ser o ponto mais distante e equidistante dos quatro problemas inibidores da criatividade, ele caracteriza o estado de clareza súbita no qual compreensão e capacidade de expressão se misturam, possibilitando não apenas a idealização, mas a materialização da criação. "Paz de espírito", "êxtase", "felicidade", "iluminação" ou qualquer outro substantivo vinculado ao momento criativo, portanto, deixa de possuir relação de causa e efeito e torna-se uma consequência da própria condição gerativa da cognição.

Existem infinitos caminhos para se alcançar o I Spot. Meditar, ou seja, cessar toda a atividade mental, é uma delas, pois seu praticante anularia os quatro vetores mentais simultaneamente, atingindo um equilíbrio de desvio padrão zero, o que acarretaria, todavia, em um resultado nulo em termos de produção. Partindo desse exercício, qualquer hábito mental, técnica criativa ou elemento contextual utilizado para elevar de forma balanceada a somatória dos dois eixos, resulta em atitudes concretas de engenho, chegando ao nível da reconhecida consciência visionária. Em síntese, pode-se dizer que prever e modelar o futuro cada vez mais distante é a medida da criatividade, definição muito empregada pelo sociólogo De Masi (2002/2003).

Nisso, acrescenta-se o terceiro eixo do modelo, no qual o desvio padrão, único valor absoluto e resultante dos demais, é 


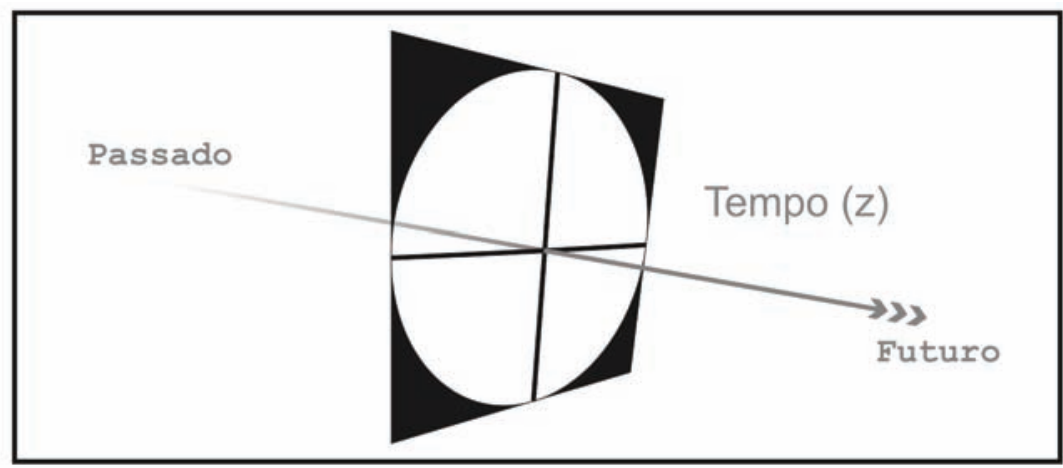

Figura 4. Eixo do tempo [vetor cinza].

rebatido na também única grandeza absoluta, o tempo (Figura 4). Matlin (2003/2004), utilizando a alegoria da subida-demorro, demonstra que a capacidade de superação da crescente complexidade das constantes bifurcações de qualquer trajeto é paralela à amplitude de visão dos próximos degraus, cujo real benefício só se constata após algumas ramificações. Estar adiante do seu tempo, portanto, decorre da prática de tomar decisões ignorando as probabilidades advindas do passado, apostando em um cenário virtual presente - concreto - exclusivamente para si, dada a sua configuração neural.

Raras, ainda, são aquelas pessoas que conseguem desenvolver, ao mesmo tempo, os padrões de pensamento lógico, intuitivo, extrovertido e reflexivo, tornando a demanda por gênios sempre maior que a sua oferta, já que a inovação é condição sine qua non para o desenvolvimento econômico, sendo a criatividade sua força motriz (Miller \& Morris, 1998). Uma alternativa bastante incentivada é o trabalho sinérgico de pessoas com traços complementares, tais como um humorista, um filósofo, um artista plástico e um matemático, compondo um grupo criativo (Claxton \& Lucas, 2004/2005; De Masi, 2002/2003), o qual produziria resultados potencialmente mais amplos no eixo $\mathrm{Z}$ do modelo.

Indivíduos e coletividades podem ser mapeados dentro desta proposta, produzindo resultados distintos entre si, já que alguém nada criativo pode ser considerado uma peça fundamental para o equilíbrio do conjunto. Nesse viés, as propostas de medição dos itens que compõem o construto variam entre os índices de criatividade (O'Reilly \& cols., 2001), os inventários de personalidade (Julien \& cols., 2007), as escalas de opinião (Dollinger, 2007), as técnicas de neurofeedback (Fink \& cols., 2007) e, até mesmo, o volume de patentes concedidas (De Masi, 2002/2003). Sem se aprofundar nas medidas psicológicas, pois essas fogem ao objetivo deste artigo, menciona-se, apenas, que o seu emprego ao mesmo tempo valida e torna prático o presente modelo.

\section{Discussão}

Redigido na forma de um ensaio crítico-analítico, este texto buscou compartilhar a proposta do autor no que se refere à compreensão do fenômeno da criatividade, a qual, em suma, consiste da adição equilibrada dos quatro principais vetores que compõem a cognição humana: a lógica, a intuição, a extroversão e a reflexão. Além de prover uma possível base comum aos demais estudos dessa mesma linha, o modelo apresentado também possibilita intervenções nas áreas educacional, empresarial e social, já que, a exemplo das demais ciências da saúde, a psicologia considera o estado de equilíbrio dinâmico aquele em que jaz o ideal estrutural e funcional dos organismos.

Em um crescente nível de complexidade, encontra-se na configuração e no tipo de ligação da rede neural a base do pensamento humano, modelando um segundo nível no qual residem os eixos da criatividade que, quando simétricos, culminam no terceiro estágio, o estado de produção criativa em si. Seguindo o mesmo princípio, as patologias de ordem estrutural (psicopatia, esquizofrenia, TDAH e TOC) se manifestam por decorrência de um desequilíbrio primário, sendo mais comuns e caóticos os problemas resultantes das interações limítrofes (o medo, o orgulho, a raiva e o fanatismo). Uma primeira sugestão de pesquisa aos interessados em dar prosseguimento a esta proposta é o afunilamento desses conceitos, pois na tentativa de evitar a sobrecarga de informações, percebe-se que ambas as definições e particularidades de cada item individual foram postas em detrimento neste artigo que introduz o seu relacionamento.

Outros caminhos a serem seguidos são a psicometria do fenômeno, a análise histórica dos casos de reconhecida criação, o desenvolvimento de paralelos entre os estados mentais individuais e o seu reflexo social e a elaboração de métodos de estímulo - e ensino - da criatividade, segregando os seus mitos da realidade. Uma dessas tradições, a que vincula criatividade e pensamento divergente, contudo, pode ser interpretada como fato, caso se aceite que, necessariamente, para atingir o I Spot é preciso buscar o complemento, logo, o diverso, desde que esse último não consista de uma classe específica, mas apenas de um oposto. Como diria Goldberg (2001/2002), "num plano mais comum, tenho frequentemente sentido que as pessoas mais dotadas de meu ambiente pessoal pagaram um preço pelo seu talento em outras áreas de sua vida mental, e que o equilíbrio entre dom e déficit é governado por alguma equação impiedosa de soma zero" (p. 218). Mesmo que isso seja real quanto à fluência e ao grau de divergência, o desvio padrão dessa soma faz com que a criatividade continue se manifestando ao longo do tempo e que as suas contribuições não se restrinjam à média. 


\section{Referências}

Amabile, T., \& Gryskiewicz, N. (1989). The creative environment scales: Work environment inventory. Creativity Research Journal, 2, 231-253.

Apolloni, B., \& Bassis, S. (2007). A feed-forward neural logic based on synaptic and volume transmission. Brain Research Reviews, 55, 108-118.

Baxter, M. (2000). Projeto de produto: guia prático para o design de novos produtos (I. Iida, Trad.) (4a ed.). São Paulo: Edgard Blücher (Trabalho original publicado em 1995).

Baylor, A. (1997). A three-component conception of intuition: Immediacy, sensing relationships, and reason. New Ideas in Psychology, 15, 185-194.

Belojevic, G., Splepcevic, V., \& Jakovljevic, B. (2001). Mental performance in noise: The role of introversion. Journal of Environmental Psychology, 21, 209-213.

Boden, M. (1999). O que é a criatividade? Em M. Boden (Org.), Dimensões da criatividade (pp. 81-123) (P. Theobald, Trad). Porto Alegre: Artes Médicas (Trabalho original publicado em 1996).

Bogacz, R. (2007). Optimal decision-making theories: Linking neurobiology with behaviour. Trends in Cognitive Sciences, 11, 118-125.

Brendtro, L., \& Longhurst, J. (2005). The resilient brain. Reclaiming Children and Youth, 14, 52-60.

Claxton, G., \& Lucas, B. (2005). Criative-se (C. Bonamine, Trad.). São Paulo: Gente (Trabalho original publicado em 2004).

Cramond, B. (1994). The relationship between attention-deficit hyperactivity disorder and creativity [Resumo]. Anais do $61^{\text {th }}$ Annual Meeting of the American Educational Research Association. Nova Orleans, Estados Unidos.

Coricelli, G., Dolan, R., \& Sirigu, A. (2007). Brain, emotion and decision making: The paradigmatic example of regret. Trends in Cognitive Sciences, 11, 258-265.

De Bonno, E. (2002). O pensamento lateral (E. Alves, Trad.) ( $3^{\text {a }}$ ed.). Rio de Janeiro: Nova Era (Trabalho original publicado em 1967).

De Masi, D. (2003). Criatividade e grupos criativos (L. Manzi, Trad.). Rio de Janeiro: Sextante (Trabalho original publicado em 2002).

Dietrich, A. (2007). Whos's afraid of a cognitive neuroscience of creativity? Methods, 42, 22-27.

Dollinger, S. (2007). Creativity and conservatism. Personality and Individual Differences, 43, 1025-1035.

Duffau, H. (2006). Brain plasticity: From pathophysiological mechanisms to therapeutic applications. Journal of Clinical Neuroscience, 13, 885-897.

Eysenck, H. (1999). As formas de medir a criatividade. Em M. Boden (Org.), Dimensões da criatividade (pp. 203-244) (P. Theobald, Trad). Porto Alegre: Artes Médicas (Trabalho original publicado em 1996).

Fink, A., Benedek, M., Grabner, R., Staudt, B., \& Neubauer, A. (2007). Creativity meets neuroscience: Experimental tasks for the neuroscientific study of creative thinking. Methods, 42, 68-76.

Galvão, M. (1999). Criativamente ( $2^{\mathrm{a}}$ ed.). Rio de Janeiro: Qualitymark.

Gardner, H. (1999). Os padrões dos criadores. Em M. Boden (Org.), Dimensões da criatividade (pp. 149-163) (P. Theobald, Trad). Porto Alegre: Artes Médicas (Trabalho original publicado em 1996).
Goldberg, E. (2002). O cérebro executivo: lobos frontais e a mente civilizada (R. Fiker, Trad.). Rio de Janeiro: Imago (Trabalho original publicado em 2001).

Gombrich, E. (1999). A história da arte (A. Cabral, Trad.) (16 ed.). Rio de Janeiro: LTC (Trabalho original publicado em 1950).

Julien, D., O’Connor, K., \& Aardema, F. (2007). Intrusive thoughts, obsessions, and appraisals in obsessive-compulsive disorder: A critical review. Clinical Psychology Review, 27, 366383.

Kalenscher, T., Ohmann, T., \& Güntürkün, O. (2006). The neuroscience of impulsive and self-controlled decisions. International Journal of Psychophysiology, 62, 203-211.

Kolb, B., \& Whishaw, I. (2002). Neurociência do comportamento (All Tasks, Trad.). Barueri, SP: Manole (Trabalho original publicado em 2001).

Kuhn, T. (1992). A estrutura das revoluções cientificas (B. Boeira, Trad.) ( $3^{\mathrm{a}}$ ed.). São Paulo: Perspectiva (Trabalho original publicado em 1962).

Manzini, E. (1993). A matéria da invenção. Lisboa: Centro Português de Design.

Martindale, C. (1999). Como podemos medir a criatividade de uma sociedade? Em M. Boden (Org.), Dimensões da criatividade (pp. 165-202) (P. Theobald, Trad). Porto Alegre: Artes Médicas (Trabalho original publicado em 1996).

Mason, G., Clubb, R., Latham, N., \& Vickery, S. (2007). Why and how should we use environmental enrichment to tackle stereotypic behaviour? Applied Animal Behaviour Science, 102, 163-188.

Matlin, M. (2004). Psicologia cognitiva (S. Machado, Trad.) (5 ed.). Rio de Janeiro: LTC (Trabalho original publicado em 2003).

McInerny, D. (2006). Use a lógica: um guia para o pensamento eficaz (F. Pantoja, Trad.). Rio de Janeiro: BestSeller (Trabalho original publicado em 2004).

Miller, W., \& Morris, L. (1998). Fourth Generation R\&D. Nova Iorque: John Wiley \& Sons.

Munari, B. (1998). Das coisas nascem coisas (J. Vasconcelos, Trad.). São Paulo: Martins Fontes (Trabalho original publicado em 1981).

Munro, G., Dywan, J., Harris, G., McKee, S., Unsal, A., \& Segalowitz, S. (2007). Response inhibition in psychopathy: The fontal n2 and p3. Neuroscience Letters, 418, 149-153.

O'Reilly, T., Dunbar, R., \& Bentall, R. (2001). Schizotypy and creativity: An evolutionary connection? Personality and Individual Differences, 31, 1067-1078.

Ostrower, F. (2002). Criatividade e processos de criação $\left(16^{\mathrm{a}}\right.$ ed.). Petrópolis: Vozes.

Perkins, D. (1999). Criatividade: além do paradigma darwiniano. Em M. Boden (Org.), Dimensões da criatividade (pp. 125-147) (P. Theobald, Trad). Porto Alegre: Artes Médicas (Trabalho original publicado em 1996).

Pinheiro, I. (2004). Método criativo em design: uma proposta com base nas áreas da inteligência artificial, psicologia, metodologia de projetos e criação de produtos. Estudos em Design, 12, 37-51.

Pinheiro, I., \& Hartamann, J. (2005). A criatividade nas organizações corporativas: o estudo de alguns casos no Rio Grande do Sul [Resumo]. Anais do XI Seminário de Gestão Tecnológica da ALTEC (CD-ROM). Salvador. 
Pinheiro, I., \& Pinheiro, I. (2005). Estimulando a solução criativa de problemas: casos em gestão e design [Resumo]. Anais do XI Seminário de Gestão Tecnológica da ALTEC (CD-ROM). Salvador.

Pinheiro, I., \& Pinheiro, I. (2006). O recurso à criatividade: estratégia para aumentar a eficiência e promover a inovação [Resumo]. Anais do XXIV Simpósio de Gestão da Inovação Tecnológica da ANPAD (CD-ROM). Gramado.

Predebon, J. (1997). Criatividade: abrindo o lado inovador da mente. São Paulo: Atlas.

Rietzschel, E., Nijstad, B., \& Stroebe, W. (2007). Relative accessibility of domain knowledge and creativity: The effects of knowledge activation on the quantity and originality of generated ideas. Journal of Experimental Social Psychology, 43, 933-946.

Sakagami, M., Pan, X., \& Uttl, B. (2006). Behavioral inhibition and prefrontal cortex in decision-making. Neural Networks, 19, 1255-1265.

Santosa, C., Strong, C., Nowakowska, C., Wang, P., Rennicke, C., \& Ketter, T. (2007). Enhanced creativity in bipolar disorder patients: A controlled study. Journal of Affective Disorders, 100, 31-39.

Schaffer, S. (1999). Caracterizando a descoberta. Em M. Boden (Org.), Dimensões da criatividade (pp. 23-58) (P. Theobald, Trad). Porto Alegre: Artes Médicas (Trabalho original publicado em 1996).
Schwartz, J. (1992). O momento criativo: mito e alienação na ciência moderna (T. Nóbrega, Trad.). São Paulo: BestSeller (Trabalho original publicado em 1992).

Seldon, H. (2007). Extended neocortical maturation time encompasses speciation, fatty acid and lateralization theories of the evolution of schizophrenia and creativity. Medical Hypotheses, 69, 1085-1089.

Sternberg, R. (2000). Psicologia cognitiva (M. Osório, Trad.). Porto Alegre: Artes Médicas (Trabalho original publicado em 1999).

Ward, T. (2007). Creative cognition as a window on creativity. Methods, 42, 28-37.

Wechsler, S. (2002). Criatividade: descobrindo e encorajando ( $3^{\mathrm{a}}$ ed.). Campinas: Livro Pleno.
Recebido em 22.08.07

Primeira decisão editorial em 17.04.08

Versão final em 25.04.08

Aceito em 24.06.08 